\title{
レーザーオリジナル 3
}

\section{オンライン計算機制御方式を用いた レーザーによる孤立重水素プラズマ生成}

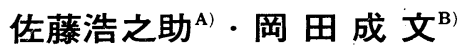

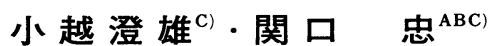

\author{
（1976年 8 月30日 受理）
}

\author{
Isolated Deuterium Plasma Production by Laser Beam \\ through On-Line Computer Control Technique.
}

\begin{abstract}
Kohnosuke $\mathrm{SATO}^{\mathrm{A})}$, Shigefumi OKADA ${ }^{\mathrm{B})}$, Sumio KOGOSHI${ }^{\mathrm{C})}$, Tadashi SEKIGUCHI ${ }^{\mathrm{ABC}}$
\end{abstract}

(Received August 30, 1976)

\begin{abstract}
A new system for directly producing impurity-free high-temperature deuterium plasmas within any type of magnetic containers has been constructed and operated, in which an on-line computer control technique is utliized to capture a falling deuterium ice-pellet by pulsed laser beam. Some experimental results on the fundamental properties of plasmas produced are presented.
\end{abstract}

\section{1.はじめに}

大出カレーザー光を物質に集光照射して作ら れるプラズマは, 他の方法では得られない特徵 を有しているが, この特徴あるプラズマと磁場 との相互作用を研究し、ひいては制御核融合へ のアプローチとしようという考え方が以前から 提案されており, 各国で小規模な予備実験が進 められていた。しかしながら，このレーザープ ラズマの特徴を真の意味で発揮させるためには, ターゲットとなる物質を真空中に何らかの方法 で“孤立”させた上で，これにレーザー光を集 光照射する必要があるが，この “孤立させて集 光照射する”という技術が，予測された以上に 困難であることが徐々に判明し，各国とも思わ しい成果を上げるに至らなかった。

以下に述べる内容は, 東京大学関口研究室で の数年の予備実験の結果 ${ }^{11}$ を基に, 名古屋大学
プラズマ研究所（客員部門）において進めさせ ていただいた，「オンライン計算機制御方式を用 いた，レーザーによる孤立重水素プラズマ生成」 に関しての話である。現在は出力 $100 \mathrm{~J}$ 程度の 5 段増幅ガラスレーザーを用いて，イオンエネル ギー $600 \mathrm{eV}$ 程度, イオン総数約 $10^{17}$ コの重水素 プラズマが生成されている。

\section{2. システムの基本的条件及び性能}

\section{1 基本的条件及び概要}

オンライン計算機制御を用いた，孤立重水素 プラズマ生成システムを考えていく場合，まず 初めに，系が有効に動作をするための条件を明 確にしておく必要がある。システムの処理時間 及び誤差に関する必要条件としては, 次の 3 点 が挙げられる。すなわち，
(a) $T_{\text {fall }}>T_{\text {control }}=\sum \tau_{i}$
(b) $\left|D_{\mathrm{F}}-D_{\mathrm{P}}\right| \geq \Delta x=\Sigma \Delta x_{i}$

A) 名古屋大学プラズマ研究所 (464 名古屋市千種区不老町)

B) 東京大学理学部, C) 東京大学工学部 (113 東京都文京区本郷)

A) Institute of Plasma Physics, Nagoya University (Furocho, Chikusa-ku, Nagoya 464)

B) Dept. of Physics, University of Tokyo, C) Dept. of Electrical Eng., University of Tokyo(Hongo, Bunkyo-ku, Tokyo 113) 
(c) $\left|D_{\mathrm{F}}-D_{\mathrm{P}}\right| \geqslant v \Delta t=v \sum \Delta t_{i}$

但し, $T_{\text {fall }}$ : 系が制御を開始してからペレット がプラズマ生成地点に落下してく るまでの時間

$T_{\text {control }}$ : 系の処理所要時間

$\tau_{i} \quad$ : 各処理での所要時間

$D_{\mathrm{F}} \quad$ ：レーザー集光スポット径

$D_{\mathrm{P}} \quad$ : ペレット径

$\Delta x, \Delta x_{i}$ : 位置に関する総合及び各部分での 誤差

$\Delta t, \Delta t_{\imath}$ ：時間に関する総合及び各部分での 誤差

$v \quad ：$ プラズマ生成水平面でのペレット 速度

これらの条件を十分満足するよう，各部分の機 構を検討しつつ組み上げたものが，以下に述べ る所の, 孤立重水素プラズマ生成装置である。 概略図をFig. 1 に示す。

液体ヘリウムタンクを内蔵した固体重水素ペ
レット生成器が, 真空容器の上部に取り付けら れており，パイプ内で生成されたペレット（ $200 \mu \mathrm{m})$ は, 適当な温度コントロールにより比 較的静かに自由落下を開始する。システムとし ては, ペレット検出系・軌道計算系・及び集光 レンズ駆動系より成っており，これらの間の情 報のやりとりの役をインターフェイスが受け持 つ。

ペレットの検出法としては光学的手段を用い るのが最も適当と考えられるが，その中でもぺ レットの影を使う方法と, 反射・屈折光などを 使う方法とに大別される。検出のための光学系, ペレットのサイズ, 自由落下の速度等, 具体的 数值を用いて色々と検討を行なうと, 後者の反 射屈折光を用いる方法が多少優っていることが 判明し，この方法を採用している。スリットは Fig. 2のような “Z型”をしたものを用いており， これらと光電子増倍管により得られたパルス列 は, インターフェイスでの波形処理の後, RUN

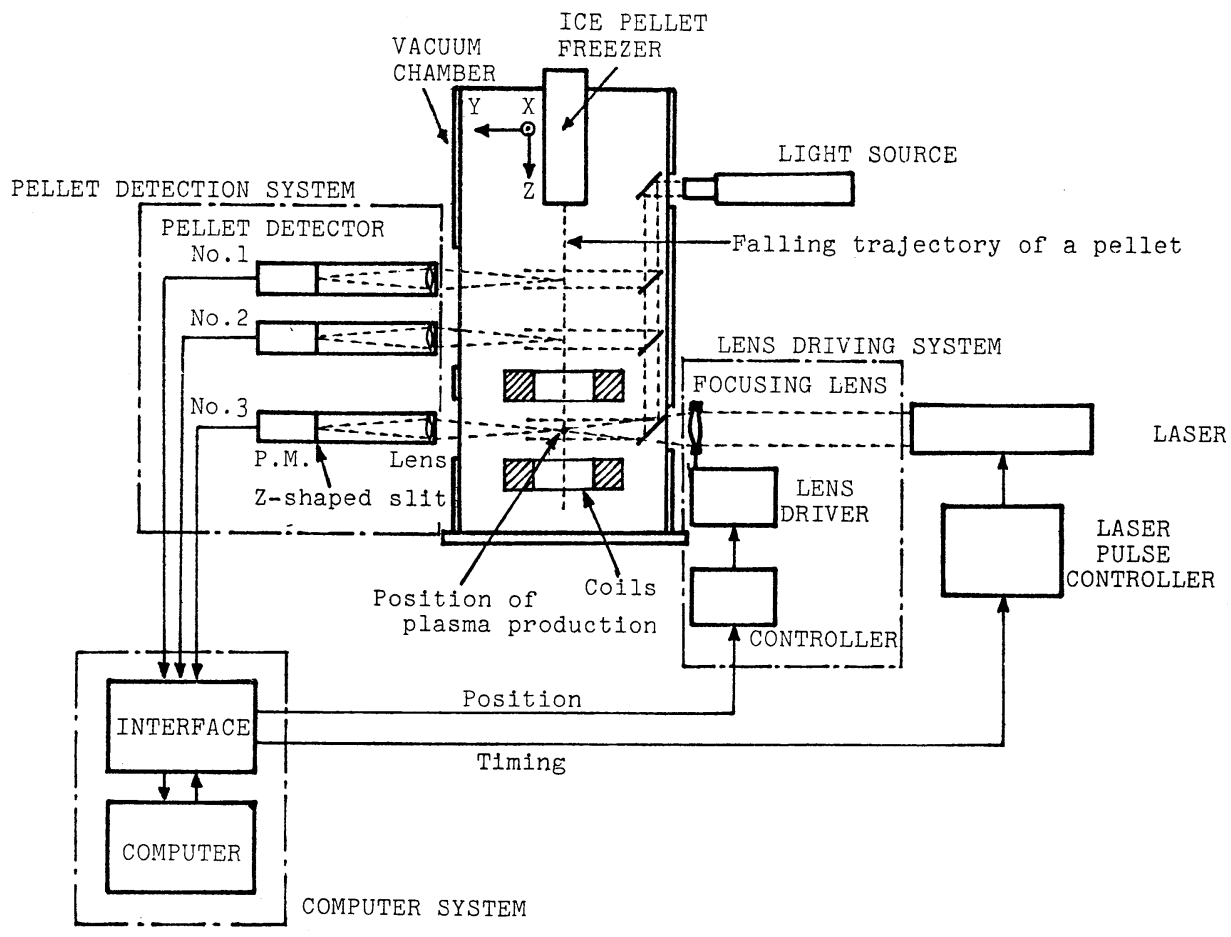

Fig. 1. Experimental arrangement, employing "on-line computer control" technique for capturing a freely falling deuterium ice-pellet by pulsed laser beam. 


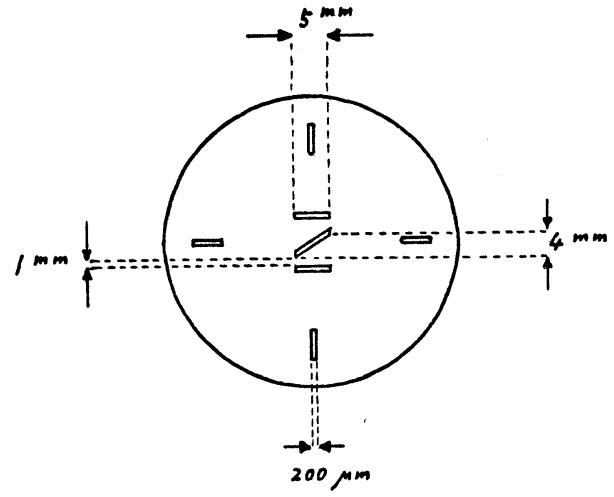

Fig. 2. Z-shaped slit

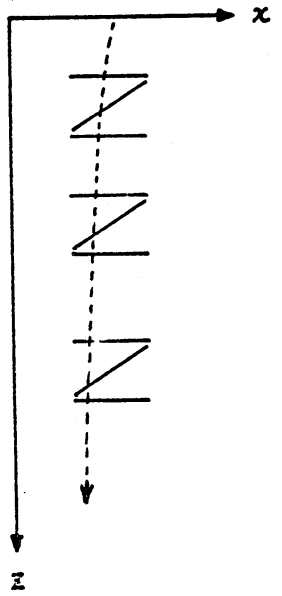

状態で待ち受けている CPUへ割り込みがかけ られる。こうすることにより CPU 処理時間を 短縮できる。軌道計算及びプラ.ズマ生成予定水 平面での空間・時間に関する予測計算が終わる と, 結果が再びインターフェイスに送り込まれ る。

これらの情報の内, 先ず位置に関するものが 高速ステップモーター駆動系に送られ，わず かな遅延の後駆動指令が出される。レーザー光 集光点の移動は, ステップモーターによって集 光レンズを駆動させる方法をとっている。他に も，例えばミラー・プリズム等の角度を振る方 法とか, 別のアプローチによる方法が考えられ るが, レーザー光の強度, 必要な移動距離, 必 要な応答速度及びそれに対する負荷（素子の重 量）等々を考慮すると, 集光レンズの移動がこ の目的には一番適していると考えられる。

インターフェイスからの指令により集光レン ズの駆動が完了すると, 移動完了信号がインタ ーフェイスに戻され，CPUはいつでもレーザ 一トリガー信号を出せる状態となり，軌道計算 からの予測された時刻がやってくるとレーザー が発射されることになる。

2.2 性能

システム全体を動作させてプラズマを生成す る前に，まずこのシステムは果して前述の基本 条件を満足しているかどうか, という点を確か
めておく必要がある。

条件 $(\mathbf{a})$, すなわち処理速度が十分速いかどう かつまりペレットが落下してくるまでに処理が 終わっているかどうかという点は，比較的容易 にチェックできる。設計の段階では, やってみ なければ分らない点をを多小含んではいるが, 実際やってみると,

$$
\begin{aligned}
& \tau_{c} \cong 2 \mathrm{~ms} \\
& \tau_{l} \cong\left\{\begin{array}{lll}
0.94 \mathrm{~S} & \mathrm{~ms} & (0 \leqq \mathrm{~S}<20) \\
0.39 \mathrm{~S}+4 & \mathrm{~ms} & (20 \leqq \mathrm{~S} \leqq 80)
\end{array}\right. \\
& \tau_{t} \cong 1 \mathrm{~ms}
\end{aligned}
$$

となる。但し, $\tau_{c}, \tau_{l}, \tau_{t}$ は各々, 軌道計算, ンズ駆動, 及びレーザー発振に要する時間, ま た $\mathrm{S}$ は, ステップモーターの駆動ステップ教で ある。現在の実験状況（落下距離 $=35 \mathrm{~cm}$, 第 2 検出器の水平面からプラズマ生成水平面までの 距離 $=15 \mathrm{~cm} ）$ では， $T_{\mathrm{fall}} \cong 65 \mathrm{~ms}$ であり，レンズ 駆動の距離が最大 $(x= \pm 4 \mathrm{~mm}, \mathrm{~S}=80)$ の場合 でも,

$$
T_{\text {fall }}>T_{\text {control }}
$$

は十分満足されている。なおこの条件は, ペレ ットの落下距離を大きくとればとる程容易に満 足されることになるわけで, このシステムが大 型の磁気閉じ込め装置に適用し得ると言われて

* 例えば計算処理速度 


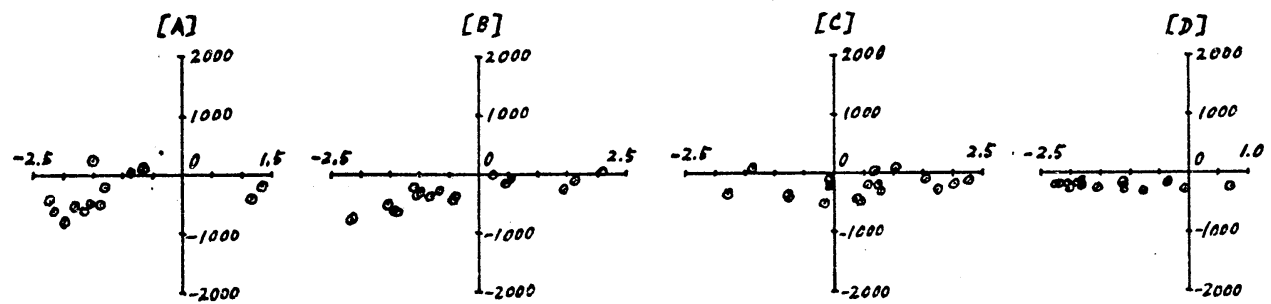

Fig. 3. Errors of anticipated values in position from No. 1 and 2 detectors' information compared with No. 3 detector's one as to various targets. Abscissa: Position of pellet at No. 3 detector's level $\left(x_{3}: \mathrm{mm}\right)$. Ordinate: Errors $\left(\Delta x_{3}: \mu \mathrm{m}\right)$. [A] Alcohol droplet: $\Delta \mathrm{X}=250 \mu \mathrm{m}$, [B] Glass pellet: $\Delta \mathrm{X}=$ $188 \mu \mathrm{m},[\mathrm{C}]$ Glass pellet with heavy material: $\Delta \mathrm{X}=152 \mu \mathrm{m}$, and [D] $\mathrm{Hg}$ droplet: $\Delta \mathrm{X}=53 \mu \mathrm{m}$.

いる要因の一つとなっている訳である。

次に条件 $(\mathrm{b})(\mathrm{c})$ であるが, これを確かめる方法 として模似ペレットを落下させてみる方法が考 えられる。模似ペレットによるテストの場合, 実験頻度及び容易さを考えると大気中でのテス トが望ましいが，この際問題となるのが空気抵 抗である。Fig. 3 に示すように, 各種の模似ぺ レットをテストしてみた結果, $\mathrm{Hg}$ の液滴が一番 望ましいことが判明した。検出系において特殊 な“Z型スリット”を採用しているため, もし 空気抵抗が効いていれば検出及び計算による位 置の誤差はペレット通過水平位置 $(x)$ に依存し, 結果として標準偏差も大きくなる。 $\mathrm{Hg}$ の場合の 偏差約 $50 \mu \mathrm{m}$ という值は，スリット巾が $200 \mu \mathrm{m}$ である事を考えると十分小さな值と言え，また この系の設計時の予想誤差*ともかなり近い。

これらの事を大気中で確認した上で, キセノ ンのペレットを真空中で落下させ系全体のテス

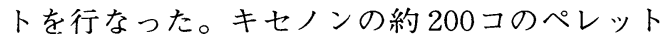
に関する結果は，ほほ予想された通りで総合溃

*検出系レンズの収差, 各検出器の水平度, 波形処理 計算処理等に由来する誤差。ステップモーターも 1 step 当り $50 \mu \mathrm{m}$ で動作させる設計。なお Fig. 4 に示 すように, $x$ (水平方向位置) 及び $t$ (時刻)に関し ての誤差は,

$$
\begin{aligned}
\Delta x_{3} & =\Delta x_{3}{ }^{\mathrm{D}}+\Delta x_{3}{ }^{\mathrm{C}}+\Delta x_{3}{ }^{\mathrm{L}} \\
& =\Delta x_{3}{ }^{\mathrm{A}}+\Delta x_{3}{ }^{\mathrm{L}} \\
\Delta t_{3} & =\Delta t_{3}{ }^{\mathrm{D}}+\Delta t_{3}{ }^{\mathrm{C}}+\Delta t_{3}{ }^{\mathrm{L}} \\
& =\Delta t_{3}{ }^{\mathrm{A}}+\Delta{t_{3}}^{\mathrm{L}}
\end{aligned}
$$

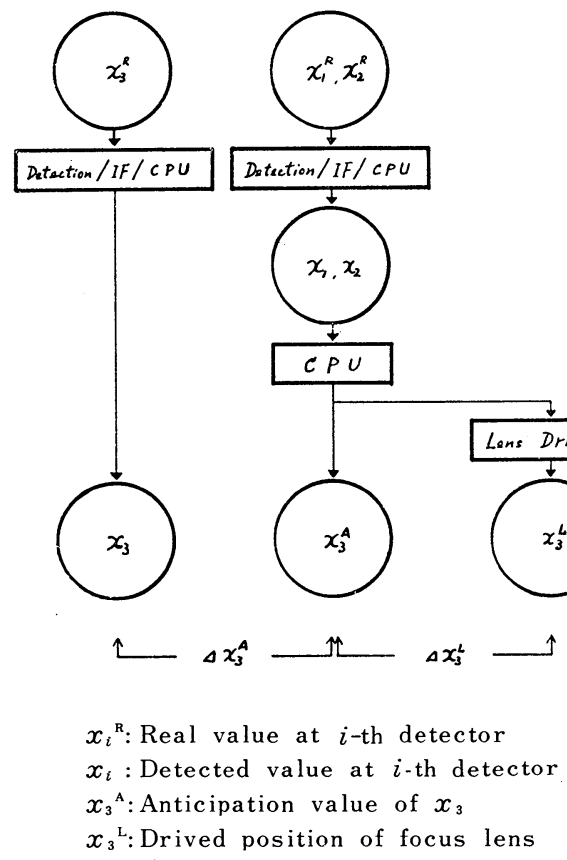

Fig. 4. Diagram of errors through processing.

差は〜 $\mathrm{D}_{\mathrm{P}} /(2 \sim 3)$ 程度におさまっており， 実験の要求から言って条件は十分満足されてい る。

なお，時間とともにペレットの初期の位置及 び速度がどの様な変化をするかを示したのが, Fig. 5 である。これらから, オンライン計算機 制御を行なうことの必要性が推察できる。

\section{3.プラズマ生成}

である。

このシステムが総合的に確実に動作するかど 

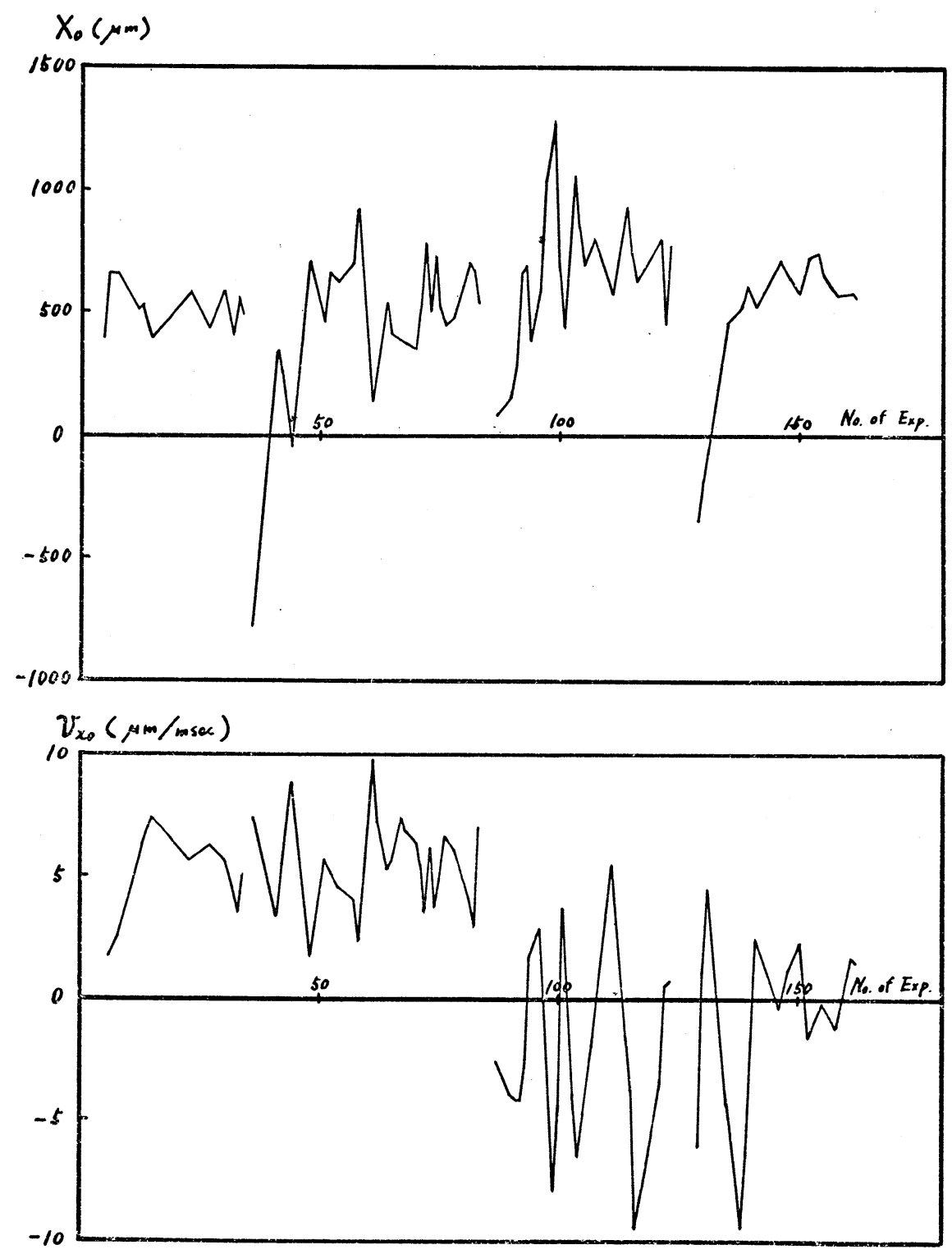

Fig. 5. Time history of fluctuations of pellets as to position and initial velocity.

うかは, 前節での誤差の問題に加えて, 鉛直軸 の軸合サ,レーザー光と連続参照光との軸合せ， レーザー光集光点と鉛直軸との合致等々の問題 があり，最終的にはペレットにレーザー光を照 射して，プラズマの再現性を確かめる必要があ る。

予測計算の結果の内, 空間または時間に関し て意図的にある量 $\left(\Delta \tau_{d}, \Delta x\right)$ だけずらせる事に
より，プラズマの生成率及び生成されたプラズ マのイオンエネルギーがどう変化するかを示し たのが, Figs.6,7である。Fig. 6 のフラット な部分及び立上りの部分からわかるように, 200 〜300 $\mu \mathrm{m}$ のペレットに対してレーザーを $700 \mu \mathrm{m}$ 程度の集光径で照射した場合, 誤差は小さく, 数百 $\mu \mathrm{m}$ の範囲にわたって $\alpha$ (プラズマ生成率 $)=$ 1 であり従って中心を狙えば確実に生成できる 
ことが判る。また, Fig. 7 は中心領域で, 生成

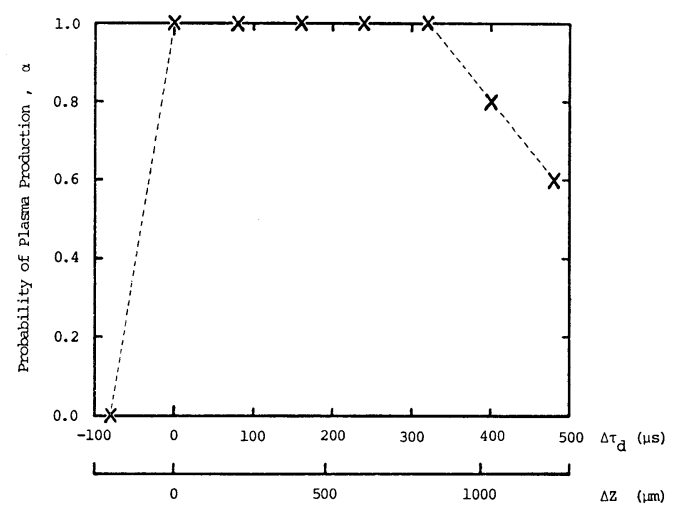

Intentional Deviation in Laser-Triggering Time

Fig. 6. Overall probability of successful plasma production

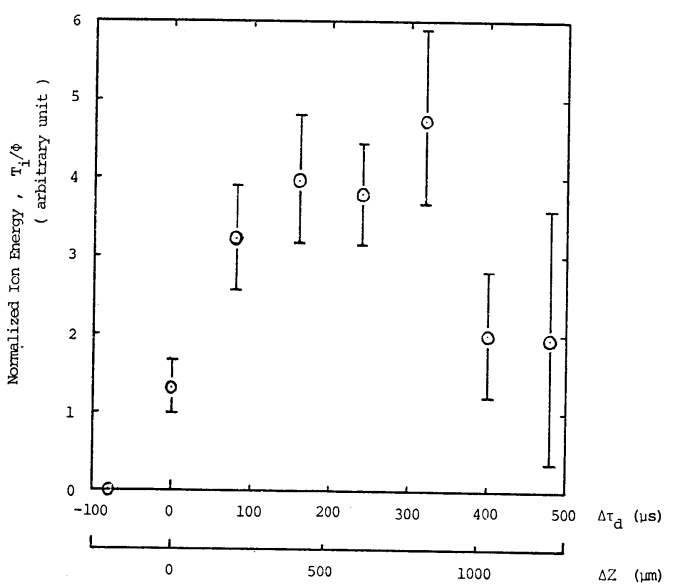

Intentional Deviation in Laser-Triggering Time

(a)

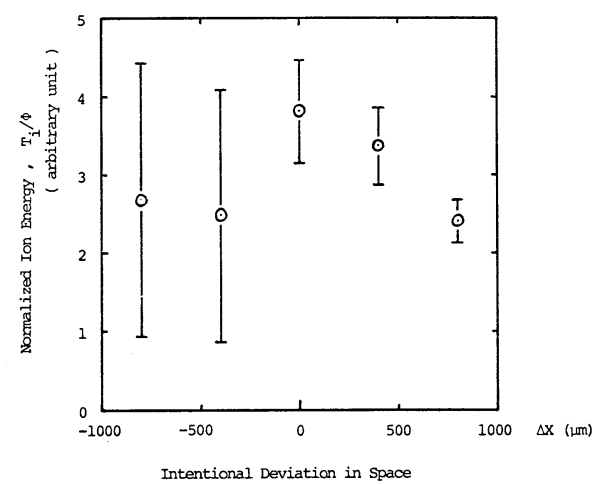

(b)

Fig. 7. Reproducibility of ion energy of plasma produced,

(a)vs. the intentional deviation in laser-triggering time, $\left(\Delta \mathrm{Z}=v \Delta \tau_{d}\right)$ and (b) vs. the intentional deviation in space.
されたプラズマのイオンエネルギーの再現性が 良いことを示している。Fig. 8 に，生成された プラズマの発光積分写真及びレーザー光透過焼 付パターンを揭げた。

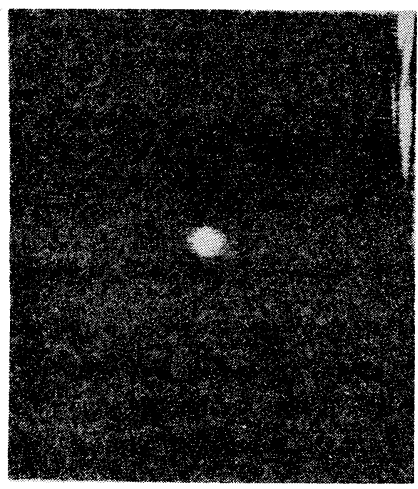

(a)

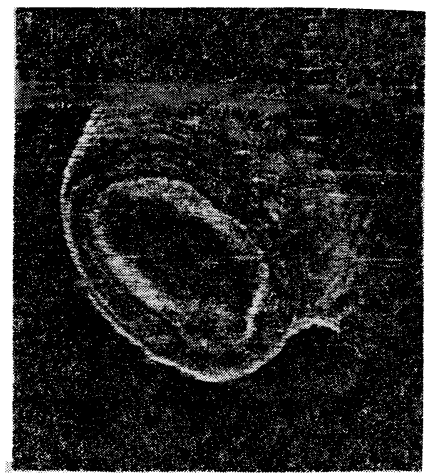

(b)

Fig. 8 (a) Time-integrated photograph of plasma light.

(b) Burned pattern of the laser light in the presence of plasma produced.

今後このシステムを用いて, プラズマの温度 ・等方性などが，レーザーパラメーター等によ つてどの様な特性を示すかを調べていく必要が あるが，一部既に得られている結果を Figs. 9, 10 に示す。なお, イオンコレクター・軟X線等 の測定から，現在イオンエネルギー約 $600 \mathrm{eV}$, イオン総数約 $10^{17}$ コの重水素プラズマが得られ ている。 


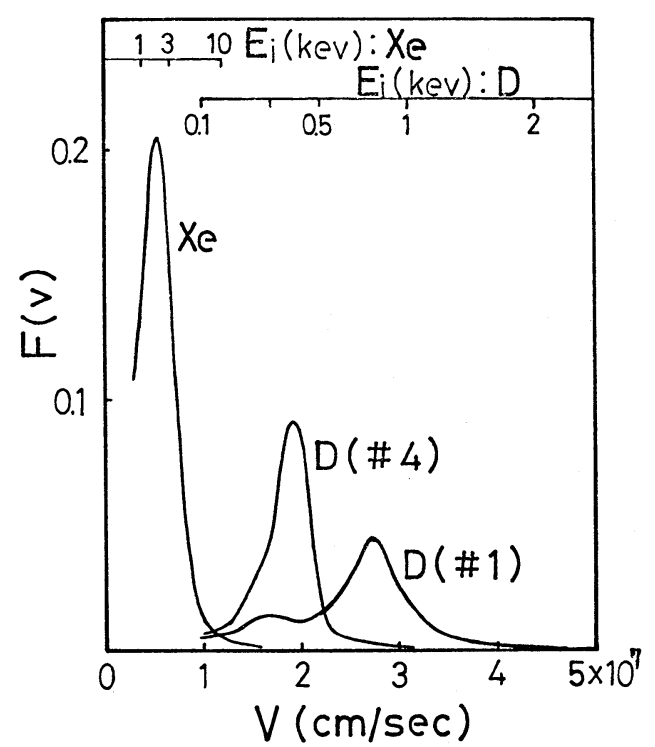

Fig. 9. Ion velocity (energy) distribution of laser-produced deuterium(D) and xenon (Xe) plasmas with a single laser beam irradiation; For $\mathrm{D}, \mathrm{W}_{\mathrm{L}} \sim 70 \mathrm{~J}, \tau_{\mathrm{L}} \sim 20 \mathrm{~ns}$ $\overline{\mathrm{E}}_{i} \sim 630 \mathrm{eV}$; for $\mathrm{Xe}, \mathrm{W}_{\mathrm{L}} \sim 20 \mathrm{~J}, \tau_{\mathrm{L}} \sim 20 \mathrm{~ns}$ and $\bar{E}_{i} \sim 2.5 \mathrm{keV}$. The three curves are normalized so as to contain the same total particle number.

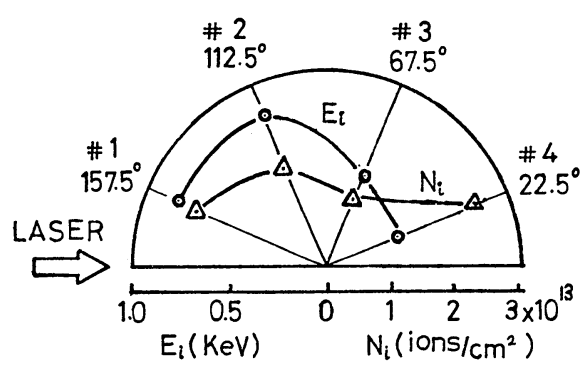

Fig. 10. Spatial anisotropy of freely expanding laser-produced D-plasma for a single laser-beam irradiation for the same conditions as in Fig. 9; $\mathrm{E}_{\iota}$ : ion energy per particle, $\mathrm{N}_{i}$ : particle number; \#1, \#2, $\cdots$ denote ion-collector, located 16 $\mathrm{cm}$ apart from the plasma origin, by which the data have been taken.

\section{4. おわりに}

世界各国でも一時試みられ，技術的困難のた めに放萧されてきた “レーザーによる孤立重水 素プラズマ生成”が，このオンライン計算機制 御方式を導入することにより，此較的再現性良 く行なえることとなった。

この方法の特徴の一つは, ペレット落下距離 が長くとれるという点にある。どこまで落下距 離を大きくできるかは制御精度ともかかわるが, ペレット生成地点から検出地点までを長くとれ ば，数 $\mathrm{m}$ にすることも可能と考えられる。精度 に関しては，検出を行なう位置を考慮すること により，比較的容易に，

$$
\Delta x \text { and } v \Delta t \leq \mathrm{D}_{\mathrm{P}} / 5
$$

程度にする事は可能と考えられている。

この研究の初期に有益な議論をしていただい た, 東京大学工学部, 田中英彦助教授, 桂井誠 助教授, 実験に際し協力して下さった, 東京大 学理学部須藤滋氏, 工学部辻博史氏, 及び技術 面で長期間助力して下さった, 名古屋大学プラ ズマ研究所技官, 深川東洋志氏に深く感謝いた します。

\section{文献}

1 ) M. Tanimoto, A. Kitsunezaki and T. Sekiguchi; J. Phys. E 5 (1972) 27.

2 ) K. N. Sato et al.; Proc. of 9 th Symposium on Fusion Technology (June 14-18, 1976, Garmisch-Partenkirchen). 